\title{
Análise das posturas adotadas durante o corte semimecanizado de jurema preta em manejo da Caatinga
}

\author{
Luciélia Lacerda da SILVA ${ }^{1}$, Pompeu Paes GUIMARÃES ${ }^{1 *}$, Ana Karla Vieira da SILVA ${ }^{1}$, \\ João Lucas Rebouças de OLIVEIRA ${ }^{1}$, Flávio Cipriano de Assis do CARMO $^{2}$, \\ Alan Cauê de HOLANDA ${ }^{1}$ \\ ${ }^{1}$ Dpto de Ciências Agronômicas e Florestais, Universidade Federal Rural do Semi-Árido, Mossoró, RN, Brasil. \\ (ORCID: 0000-0002-6994-4734; *; 0000-0002-7292-5024; 0000-0003-3279-7029; 0000-0003-1408-0075) \\ ${ }^{2}$ Centro de Saúde e Tecnologia Rural, Universidade Federal de Campina Grande, Patos, PB, Brasil. (ORCID: 0000-0001-9956-5295) \\ *E-mail: pompeu.guimaraes@ufersa.edu.br (ORCID: 0000-0003-1614-1927)
}

Recebido em 22/11/2019; Aceito em 28/05/2020; Publicado em 10/06/2020.

RESUMO: Objetivou-se com esta pesquisa analisar as principais posturas adotadas na atividade de corte semimecanizado da Mimosa tenuiflora (Willd.) Poir. popularmente conhecida como jurema preta, por meio da utilização dos métodos ergonômicos Ovako Working Posture Analysis System (OWAS), Rapid Upper Limb Assessment (RULA) e Rapid Entire Boby Assessment (REBA) além de propor melhorias no ambiente de trabalho. Foram analisadas, em cada um dos métodos, 220 posturas adotadas durante a atividade de derrubada, destopamento, toragem e condensadas em 30 codificações principais. Dado o exposto, concluiu-se que as codificações em que o operador se manteve com as costas inclinadas, inclinadas e torcida, os dois braços acima dos ombros, o antebraço com amplitudes maiores que $45^{\circ}$, com o pescoço inclinado, e o troco inclinado, além de todas as posturas que foram classificadas nas categorias ou níveis de ação que indiquem uma intervenção próxima ou imediata.

Palavras-chave: ergonomia; biomecânica; exploração florestal.

\section{Analysis of the postures adopted during the semimecanized court of jurema preta in Caatinga management}

\begin{abstract}
The objective of this work was to analyze the main postures adopted in the semimechanized cutting activity of Mimosa tenuiflora (Willd.) Poir., popularly known as black jurema, through the use of Ovako Working Posture Analysis System (OWAS), Rapid Upper Limb Assessment (RULA) and Rapid Entire Boby Assessment (REBA) in addition to proposing improvements in the work environment. In each method, 220 postures adopted during the felling, delimbing and tracing activity were analyzed and condensed into 30 main codings according to the result obtained for each of the analysis methods and further subdivided according to the activity. felling, delimbing and tracing. Given the above, it was concluded that the codings in which the operator stands with the back inclined, bent and twisted, both arms above the shoulders, the forearm with amplitudes greater than $45^{\circ}$, the forearm with amplitudes greater than $45^{\circ}$, the neck is at some angle of inclination, the inclined change, and all postures that have been classified into categories or levels of action that indicate close or immediate intervention.
\end{abstract}

Keywords: ergonomics; biomechanics; caatinga management.

\section{INTRODUÇÃO}

No Brasil, a norma regulamentadora 17 - Ergonomia (NR-17, 2012) do Ministério da Economia, visa a estabelecer parâmetros que permitam a adaptação das condições de trabalho às características psicofisiológicas dos trabalhadores, de modo a proporcionar um máximo de conforto, segurança e, por consequência, desempenho eficiente. As condições de trabalho, incluem levantamento, transporte, descarga de materiais, equipamentos e ambiente de trabalho, por exemplo e, ainda segundo a NR-17, a avaliação das condições cabe ao empregador por meio de análises ergonômicas do ambiente de trabalho.

Em relação ao trabalho florestal, a atividade de colheita florestal, parte importante do ponto de vista técnicoeconômico, é composta pelas etapas de corte (derrubada, desgalhamento, toragem e destopamento), extração e carregamento (BARBOSA et al, 2014).

Dessa forma, autores como Barbosa et al. (2014) e Silva et al. (2014), ressaltam que a colheita florestal, executada por quaisquer métodos, na grande maioria das vezes, se caracteriza como uma atividade pesada e perigosa pois, as operações exigem que o trabalho seja executado em posições desconfortáveis e com movimentos repetitivos por períodos prolongados.

Acrescenta-se também o fato da atividade ser realizada com o manuseio de cargas pesadas, máquinas e ferramentas cortantes, tais como motosserra.

Leonello et al. (2012), destaca que, a mecanização da colheita de madeira permite maior controle dos custos de produção, o que possibilita ao gestor maior suporte de 
informações a fim de obter resultados mais eficientes a curto prazo. Além disso, a adoção de máquinas tem lugar de destaque na humanização do trabalho florestal e no aumento do rendimento operacional das atividades.

Atentando para a exploração florestal na Caatinga, Maia et al. (2017), ressaltou que dentre os biomas brasileiros, a mesma é, provavelmente, o menos conhecido botanicamente e o mais desvalorizado, dada a reduzida exploração sustentável dos recursos naturais e a elevada proporção desmatamento para fins energéticos e pecuária.

Ademais, Lopes; Canto (2018), destacam que existe uma carência de estudos para subsidiar o planejamento técnico e econômico das atividades semimecanizadas de exploração sustentável de lenha, na Caatinga.

Inserido nesse contexto, o objetivo do trabalho foi analisar as principais posturas adotadas na atividade de corte semimecanizado, por meio da utilização dos métodos ergonômicos Ovako Working Posture Analysis System (OWAS), Rapid Upper Limb Assessment (RULA) e Rapid Entire Boby Assessment (REBA).

\section{MATERIAL E MÉTODOS}

\subsection{Caracterização da Espécie}

A espécie utilizada para realização dessa pesquisa foi a Jurema Preta (Mimosa tenuiflora (Willd.) Poir., do gênero Mimosa L., ocorrente na Caatinga nordestina (SILVA et al., 2011) e considerada, do ponto de vista ecológico, tipicamente oportunista e de crescimento rápido, apresentando-se assim como uma grande potencial para o reflorestamento de áreas degradadas (SANTOS- SILVA et al,. 2015).

\subsection{Caracterização do motosserra utilizado}

A motosserra utilizada neste estudo, apresenta cilindrada de $50,2 \mathrm{~cm}^{3}, 4.8 \mathrm{~kg}$ e $2,6 / 3,5 \mathrm{~kW} / \mathrm{cv}$ de potência de acordo com o manual do fabricante.

\subsection{Avaliação das Posturas}

Nesta pesquisa foram empregados três métodos de avaliação ergonômica: Ovako Working Posture Analysis System (OWAS), Rapid Upper Limb Assessment (RULA) e Rapid Entire Boby Assessment (REBA). As posturas foram subdivididas por atividade: derrubada, desgalhamento e toragem.

\subsubsection{Ovako Working Posture Analysis System (OWAS)}

Este método desenvolvido por pesquisadores finlandeses em 1977, consiste na observação das posturas, as quais foram classificadas segundo suas posições, resultando em uma codificação de quatro dígitos conforme apresentado na Tabela 1. Para as costas, os códigos 1,2, 3 e 4 indicam postura ereta, inclinada, ereta e torcida, inclinada e torcida, respectivamente. Em relação aos braços, os códigos são 1, 2 e 3 indicam os dois braços abaixo do ombro, um no nível ou acima do ombro, ambos os braços no nível ou acima dos ombros, respectivamente.

Em relação a postura das pernas foi descrita pelos códigos 1, 2, 3, 4, 5, 6 e 7 que indicam as posições sentado, de pé com ambas as pernas esticadas, de pé com o peso de uma das pernas esticadas, de pé ou agachado com ambos os joelhos flexionados, de pé ou agachado com um dos joelhos dobrados, ajoelhado em um ou ambos os joelhos e andando ou se movendo, respectivamente. Além do esforço físico que foi dado pelos códigos 1, 2 e 3 sendo carga menor que $10 \mathrm{~kg}$, carga entre 10 e $20 \mathrm{~kg}$ e carga maior do que $20 \mathrm{~kg}$, sucessivamente.

O resultado da combinação de posturas das costas, braços, pernas e uso de força permite classificar a postura em uma das quatro categorias de ação indicando as recomendações para ações corretivas em diferentes escalas de tempos:

- Categoria 1: postura normal que dispensa cuidados (exceto em casos excepcionais);

- Categoria 2: postura deverá ser verificada durante a próxima revisão de rotina de trabalho;

- Categoria 3: Postura que deve merecer atenção a curto prazo;

- Categoria 4: Postura que deve merecer atenção imediata.

Tabela 1. Categorias de ação segundo posição das costas, braços, pernas e uso de força. Fonte: (CORLETT; WILSON, 2005).

Table 1. Categories of action second position of the back, arms, legs and use of force. Source: (CORLETT; WILSON, 2005).

\begin{tabular}{|c|c|c|c|c|c|c|c|c|c|c|c|c|c|c|}
\hline \multirow{2}{*}{\multicolumn{2}{|c|}{$\begin{array}{l}\text { COSTAS } \\
\text { BRAÇOS }\end{array}$}} & & \multicolumn{3}{|c|}{1} & \multicolumn{3}{|c|}{2} & \multicolumn{3}{|c|}{3} & \multicolumn{3}{|c|}{4} \\
\hline & & & 1 & 2 & 3 & 1 & 2 & 3 & 1 & 2 & 3 & 1 & 2 & 3 \\
\hline \multirow{5}{*}{1} & 1 & 1 & 1 & 1 & 1 & 2 & 2 & 3 & 1 & 2 & 2 & 2 & 3 & 4 \\
\hline & 2 & 2 & 1 & 1 & 1 & 2 & 2 & 3 & 1 & 2 & 2 & 3 & 3 & 4 \\
\hline & 3 & 3 & 1 & 1 & 1 & 3 & 3 & 4 & 1 & 3 & 3 & 3 & 4 & 4 \\
\hline & 1 & 1 & 1 & 1 & 1 & 2 & 2 & 2 & 1 & 1 & 1 & 2 & 2 & 2 \\
\hline & 2 & 2 & 1 & 1 & 1 & 2 & 2 & 2 & 1 & 1 & 1 & 2 & 3 & 3 \\
\hline \multirow[t]{3}{*}{2} & 3 & 3 & 1 & 1 & 1 & 3 & 3 & 3 & 1 & 1 & 1 & 3 & 4 & 4 \\
\hline & 1 & 1 & 1 & 1 & 1 & 2 & 2 & 3 & 1 & 1 & 2 & 2 & 3 & 3 \\
\hline & 2 & 2 & 1 & 1 & 1 & 2 & 3 & 3 & 1 & 2 & 3 & 2 & 3 & 3 \\
\hline \multirow[t]{3}{*}{3} & 3 & 3 & 1 & 1 & 1 & 3 & 3 & 3 & 2 & 4 & 3 & 3 & 4 & 4 \\
\hline & 1 & 1 & 2 & 2 & 2 & 3 & 3 & 3 & 3 & 4 & 4 & 4 & 4 & 4 \\
\hline & 2 & 2 & 2 & 2 & 2 & 3 & 4 & 4 & 3 & 4 & 4 & 4 & 4 & 4 \\
\hline \multirow[t]{3}{*}{4} & 3 & 3 & 2 & 2 & 3 & 3 & 4 & 4 & 3 & 4 & 4 & 4 & 4 & 4 \\
\hline & 1 & 1 & 2 & 2 & 2 & 3 & 3 & 4 & 4 & 4 & 4 & 4 & 4 & 4 \\
\hline & 2 & 2 & 2 & 2 & 2 & 3 & 4 & 4 & 4 & 4 & 4 & 4 & 4 & 4 \\
\hline \multirow[t]{3}{*}{5} & 3 & 3 & 2 & 2 & 2 & 3 & 4 & 4 & 4 & 4 & 4 & 4 & 4 & 4 \\
\hline & 1 & 1 & 1 & 1 & 1 & 2 & 3 & 4 & 1 & 3 & 4 & 4 & 4 & 4 \\
\hline & 2 & 2 & 1 & 1 & 1 & 2 & 3 & 4 & 1 & 3 & 4 & 4 & 4 & 4 \\
\hline \multirow[t]{3}{*}{6} & 3 & 3 & 1 & 1 & 1 & 2 & 4 & 4 & 1 & 3 & 4 & 4 & 4 & 4 \\
\hline & 1 & 1 & 1 & 1 & 1 & 2 & 2 & 2 & 1 & 1 & 1 & 2 & 2 & 2 \\
\hline & 2 & 2 & 1 & 1 & 1 & 3 & 3 & 3 & 1 & 1 & 1 & 3 & 3 & 3 \\
\hline 7 & 3 & 3 & 1 & 1 & 2 & 3 & 4 & 4 & 1 & 1 & 1 & 4 & 4 & 4 \\
\hline & IS FOR & RÇA & & & & & & & & & & & & \\
\hline
\end{tabular}

\subsubsection{Rapid Upper Limb Assessment (RULA)}

$\mathrm{O}$ método desenvolvido por pesquisadores da Universidade de Nottingham, se baseia em uma avaliação dos membros superiores e inferiores, para isso o corpo é dividido em dois grupos, A e B. O grupo A engloba os membros superiores (braços, antebraços e punhos). Já o grupo B representa o pescoço, tronco, pernas. As posturas foram enquadradas de acordo com as angulações entre os membros e o corpo. O detalhamento das posturas dos grupos A e B, é apresentado na Tabela 2. Após a análise dos membros superiores e inferiores, foi atribuída uma pontuação final progressiva em relação ao risco de lesão daquela postura para determinado corpo. A pontuação determina o nível de ação e por consequência, uma intervenção que indica modificações posturais em diferentes escalas de tempo, sendo: 
Tabela 2. Detalhamento das posturas dos grupos A e B, de acordo com seus relativos códigos. Table 2. Detail of the postures of groups A and B, according to their relative codes.

\begin{tabular}{|c|c|c|c|c|c|c|}
\hline Códigos & 1 & 2 & 3 & 4 & 5 & 6 \\
\hline Braço & $20^{\circ}+$ & $\begin{array}{c} \pm 20^{\circ} \text { ou }+20^{\circ}- \\
45^{\circ}\end{array}$ & $45^{\circ}-90^{\circ}$ & $90^{\circ}+$ & & \\
\hline Antebraço & $0^{\circ}-60^{\circ}$ & $60^{\circ}-100^{\circ}$ & $100^{\circ}+$ & & & \\
\hline Punho & $0^{\circ}$ & $15^{\circ}-15$ & $15^{\circ}+$ & $15^{\circ}+$ & & \\
\hline $\begin{array}{l}\text { Rotação do } \\
\text { Punho }\end{array}$ & $0^{\circ}$, Rotação média & Rotação externa & & & & \\
\hline Pescoço & Extensão & $0^{\circ}-10^{\circ}$ & $10^{\circ}-20^{\circ}$ & $20^{\circ}+$ & & \\
\hline Tronco & $0^{\circ}$ & $0^{\circ}-20^{\circ}$ & $20^{\circ}-60^{\circ}$ & $60^{\circ}+$ & & \\
\hline Pernas & $\begin{array}{l}\text { Pernas e pés bem } \\
\text { apoiados e } \\
\text { equilibrados }\end{array}$ & $\begin{array}{l}\text { Pernas e pés não } \\
\text { estão apoiados e } \\
\text { equilibrados }\end{array}$ & & & & \\
\hline $\begin{array}{c}\text { Atividade } \\
\text { (Grupo A e B) }\end{array}$ & $\begin{array}{l}\text { Sem carga ou } \\
\text { menor que } 2 \mathrm{~kg} \\
\text { intermit. }\end{array}$ & $\begin{array}{c}\text { Carga entre } 2 \text { e } 10 \\
\text { kg intermit. }\end{array}$ & $\begin{array}{c}\text { Carga entre } 2 \text { e } \\
10 \text { kg estática } \\
\text { ou repetitiva }\end{array}$ & $\begin{array}{c}\text { Carga } \\
\text { superior a } 10 \\
\text { kg intermit. }\end{array}$ & $\begin{array}{c}\text { Carga } \\
\text { superior a } 10 \\
\text { kg intermit. } \\
\text { ou estática }\end{array}$ & $\begin{array}{l}\text { Há força } \\
\text { brusca e ou } \\
\text { repetitiva }\end{array}$ \\
\hline
\end{tabular}

em que intermit. $=$ intermitentemente.

Posturas com pontuação final (1-2) se enquadram no nível de ação 1: postura aceitável caso não seja mantida ou repetida por longos períodos; (3-4) são classificadas no nível de ação 2: postura a investigar e poderão ser necessárias alterações; (5-6) compreende o nível de ação 3: postura a ser analisada e alterada rapidamente; (7 ou mais), nível de ação 4: postura a ser analisada e alterada urgentemente.

\subsubsection{Rapid Entire Boby Assessment (REBA)}

O método REBA foi desenvolvido por Hignett and McAtamney no ano de $2000 \mathrm{com}$ a finalidade de avaliar os segmentos corporais separando-os em dois grupos (A e B). O grupo A consiste no tronco, pescoço e pernas, e tem 60 combinações posturais possíveis e o grupo B consiste no braço, antebraço e punho com 36 combinações possíveis (LAMARÃO et al. 2014).

$\mathrm{Na}$ análise do grupo A, considerou-se para o tronco e o pescoço, o ângulo em flexão ou extensão mais torção ou ainda, a inclinação lateral. Para as pernas, o suporte unilateral ou bilateral (caminhando ou sentado) mais o grau de flexão dos joelhos, foi levado em consideração. No grupo B, a análise do braço se deu através da observação do ângulo em flexão ou extensão mais se apresentou rotação, abdução além de ombros elevados ou se existia apoio ou posturas a favor da gravidade e em relação ao antebraço e o punho, o ângulo em flexão ou extensão, não pode ser desprezado (BATIZ et al. 2012a).

Ainda, para Batiz et al. (2012b), a pontuação subtotal do grupo A obtida após a análise dos membros do grupo, foi somada com a pontuação por força ou carga enquanto, no grupo B, o subtotal somado a pontuação por pega (agarre). A pontuação final enquadrou a referida postura em um dos níveis de ação consequentemente indicando um nível de risco e uma intervenção posterior a análise, sendo:

Pontuação final (1): nível de ação 0 , risco postural inapreciável e intervenções não se fizeram necessárias; (2-3) configura o nível de ação 1 indicando nível de risco baixo em que a intervenção pode ser necessária; (4-7) classifica nível de ação 2, risco médio onde a intervenção é necessária; (8-10), nível de ação 3 em que o risco é considerado alto e a intervenção é prontamente necessária; (11-15) tem-se o nível de ação 4 em que o risco é muito alto e a intervenção deve ser imediata.

\subsubsection{Média ponderada das categorias de ação}

Para os três métodos foram calculadas a média ponderada da categoria de ação das posturas adotadas durante cada uma das etapas da derrubada semimnecanizada de Jurema Preta com auxílio da Equação 1.

$$
\bar{X}=\frac{\left(C_{1} * R_{1}\right)+\left(C_{2} * R_{2}\right)+\cdots+\left(C_{n} * R_{n}\right)}{R_{1}+R_{2}+\cdots+R_{n}}
$$

em que: $\bar{X}=$ Categoria de ação média; $C_{i}=$ Categoria de ação no nível $i ; \mathrm{R}_{i}=$ Repetição do nível $i$.

\section{RESULTADOS}

As posturas encontradas utilizando o método OWAS, RULA e REBA podem ser visualizadas na Tabela 3, de forma que, para cada etapa, foram utilizadas as seis primeiras posturas com maior número de repetições ou seja, com maior representatividade e quatro posturas que chamaram atenção pela sua categoria ou nível de ação. A Tabela 4 se referiu a postura de maior representatividade de cada uma das etapas e de cada método de análise utilizado. O total de codificações para cada uma das partes corporais apresentadas pelo OWAS, RULA e REBA é apresentado na Tabela 3.

\section{DISCUSSÃO \\ 4.1. OWAS}

As posturas mais representativas da análise utilizando o método OWAS para a atividade de derrubada, foram codificadas como 2121- Costas inclinadas, os dois braços abaixo do ombro, de pé com ambas as pernas esticadas, carga menor que $10 \mathrm{~kg}$ e classificada na categoria 2, indicando sua verificação durante a próxima revisão de rotina de trabalho; 2141, diferindo da primeira postura apenas em relação a posição das pernas onde, uma das mesmas se encontrava flexionada, sendo classificada na categoria 3 , indicando que a referida postura merece atenção a curto prazo e, a terceira postura mais repetida foi codificada como 1121 diferindo da primeira somente em relação as costas que aqui se encontravam eretas (com categoria 1).

Considerando-se uma jornada de trabalho de $480 \mathrm{~min}$ e as duas posturas mais representativas da derrubada, $2121 \mathrm{e}$ 2141, o operador permaneceu com as costas inclinadas (2) 
por $212,2 \mathrm{~min}$, correspondendo a $44,2 \%$ do total. Segundo Dul; Weerdmeester (2012) é fundamental evitar manter-se com o corpo inclinado, visto que no momento em que se inclina para frente, há contração dos músculos e dos ligamentos das costas.

Ainda, em relação ao desgalhamento e a toragem, as codificações mais repetidas diferem da atividade de derrubada apenas pelas codificações 4121 - Costas inclinada e torcida, os dois braços abaixo do ombro, de pé com ambas as pernas esticadas, carga menor que $10 \mathrm{~kg}$ e classificada na categoria 2 , indicando sua verificação durante a próxima revisão de rotina de trabalho e 2151 - na qual as costas se encontram inclinadas (categoria de ação 2), conforme apresentado nas Tabelas 3 e 4 .

Tabela 3. Posturas padrão obtidas no corte florestal semimecanizado.

Table 3. Standard postures obtained in semi-mechanized forest logging.

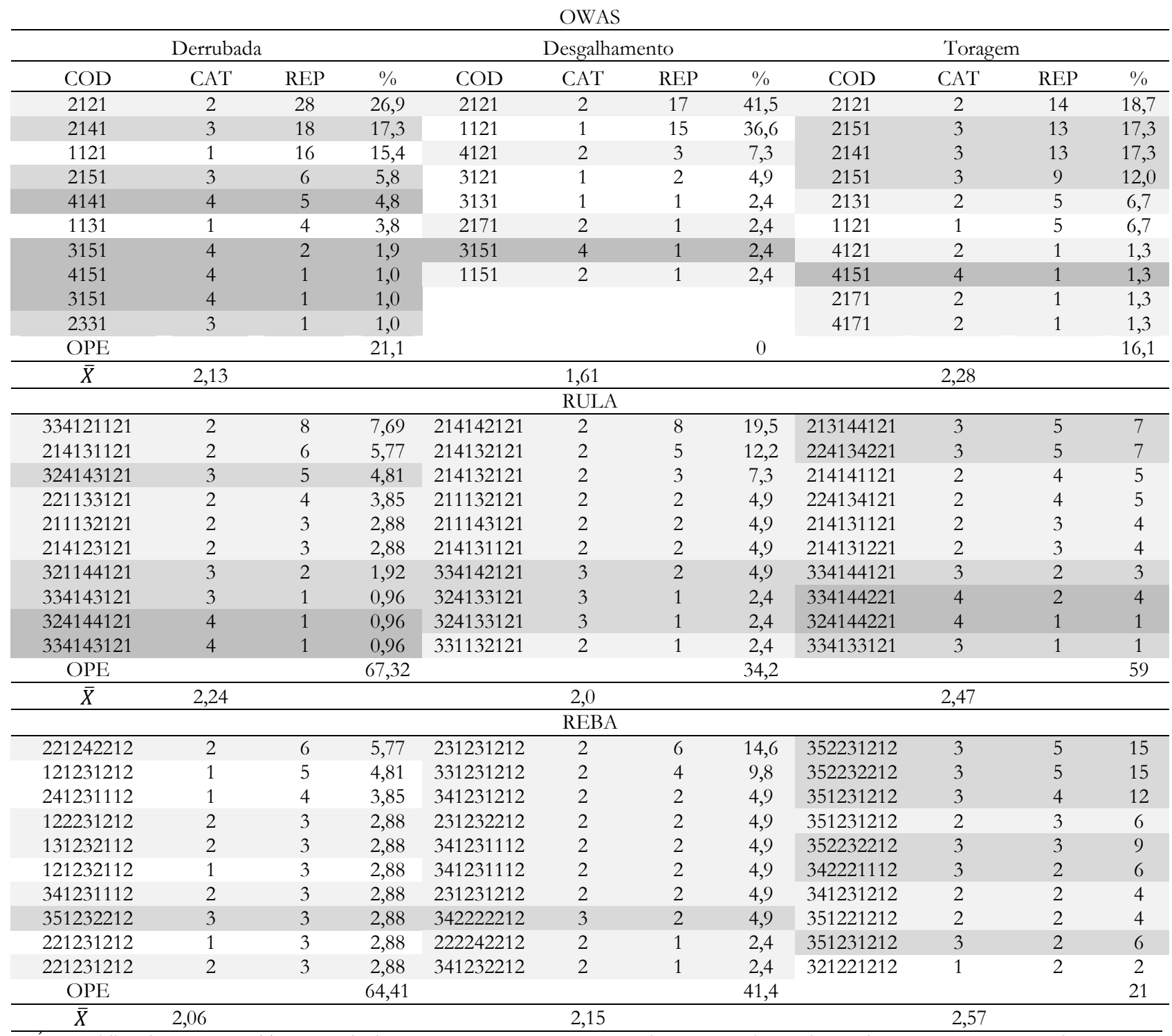

CÓD = Código da postura; CAT = Categoria de ação em que a postura se enquadra; REP= Númeto de repetições; $\%=$ Porcentagem da postura na análise;OPE $=$ Outras posturas encontradas; $\bar{X}=$ Média da categoria.

As codificações com as piores classificações em relação a categoria de ação obtidas pela análise com método OWAS, tendo em vista a repetição das tais posturas de acordo com a derrubada, desgalhamento e toragem, respectivamente foram: 4141 - costas se encontram inclinadas e torcidas (4), uma das pernas esta flexionada (4), perpetuando-se durante 23,04 min dos 480 min da jornada de trabalho diária; 3151 na qual, o dorso encontrou-se reto e torcido (3) e com uma das pernas ajoelhada (5), na qual, apesar de se encontrar na categoria de ação 4, o operador se manteria nesta posição por um curto período de tempo (11,52 min da jornada de trabalho) e 4151, com costas inclinadas e torcidas (4) e uma das pernas ajoelhada (5), totalizando 6,24 min do total.

Ao compreender todas as posturas expostas na Tabela 3 , sem distinção de atividade realizada, o operador permaneceria com as costas eretas (1) por $17,9 \%$ do período; costas inclinadas e torcidas (2) por $42,9 \%$; ereto e inclinado (3) por $17,86 \%$; inclinado e torcido (4) por $17,9 \%$ do total. Ademais, os dois braços se encontravam abaixo dos ombros (1) por $96,43 \%$ total; e os dois braços para cima (3) por 3,57\% total. Em relação as pernas, uma das pernas reta (2) foi utilizada por $32,1 \%$ do período; as duas pernas flexionadas (3) prevalecem por $14,3 \%$; uma perna flexionada (4) por $10,7 \%$ total; uma perna ajoelhada (5) por 32,1\% total; não foi 
constatado a realização de deslocamento com as pernas (6); as duas pernas suspensas (7) prevalecem por $10,7 \%$ e, sobre a carga exercida pelo operador, todo o período o mesmo se encontra carregando uma carga menor que $10 \mathrm{~kg}$.
Observando as posturas adotadas pelo operador em relação as suas costas, percebeu-se que houve uma permanência constante do trabalhador com as costas inclinadas e torcida (2), totalizando $42,9 \%$ do período.

Tabela 4. Principais posturas adotadas no corte semimecanizado da jurema preta e seus principais códigos de acordo com o método da análise e sua classificação em relação a uma etapa.

Table 4. Main postures adopted in semi-mechanized Mimosa tenuiflora felling and its main codes according to the method of analysis and its classification in relation to a stage.

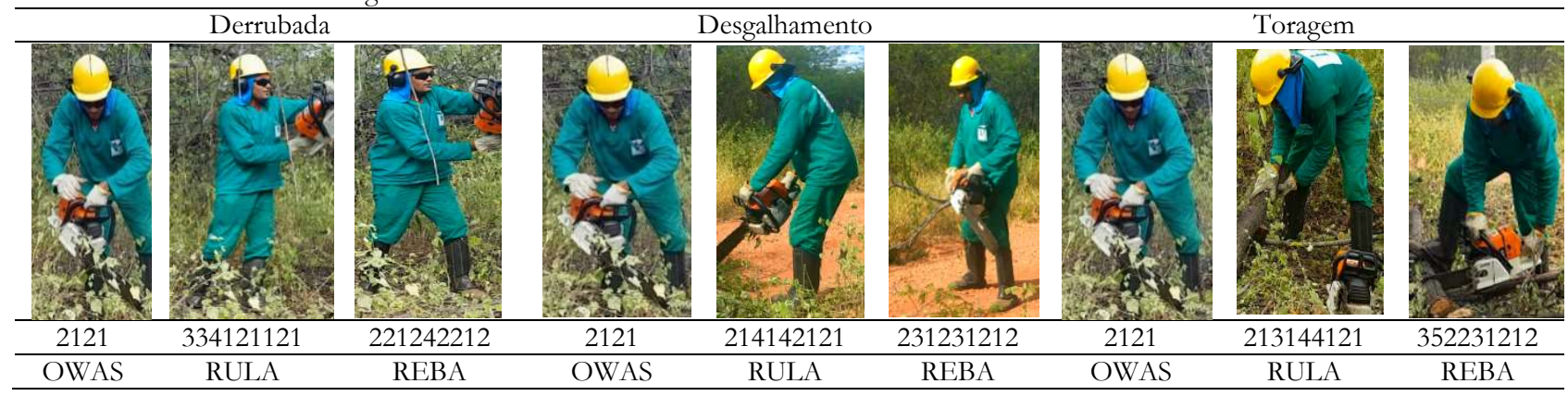

\subsection{RULA}

Em relação ao método RULA, considerando a análise postural, verificou-se que a atividade de derrubada além dos dados obtidos e descritos na Tabela 3, neste caso, a codificação 334121121 - os braços se encontravam com angulação posterior ao corpo entre $20^{\circ}$ e $45^{\circ}+$, antebraços inclinados $100^{\circ}+$, punho posicionado $15^{\circ}+$, rotação do punho com angulação média, pescoço entre $0^{\circ}$ e $10^{\circ}+$, tronco entre $0^{\circ}$ a $20^{\circ}+$, com pernas bem apoiadas e equilibradas além da carga exercida pelo grupo A, entre 2 a $10 \mathrm{~kg}$, referente ao peso da motosserra, e o grupo B se apresentou sem carga ou com carga inferior a $2 \mathrm{~kg}$ intermitentemente - foi a postura que mais se repetiu e se enquadrou no nível de ação 2 indicando a necessidade de realizar uma observação e ressaltando a possibilidade de introdução da mudanças (Tabela 4).

A segunda postura mais representativa 2141131121 diferiu-se da primeira apenas em relação ao código referente aos braços que, neste caso, se comportaram de forma a possuírem angulações entre $20^{\circ}$ posteriores ou anteriores ao corpo (2), ao antebraço (1) configurando angulação entre $0^{\circ}$ e $60^{\circ}+$ e ao pescoço que pode variar positivamente entre $10^{\circ}$ e $20^{\circ}$ (3) e ainda, se difere da terceira codificação mais representativa 324143121 no que se relação aos códigos do antebraço (2) indicando angulação entre $60^{\circ}$ e $100^{\circ}$ posteriores ao corpo além do código do pescoço aqui diagnosticado com angulação de $20^{\circ}+(4)$ e no que concerne ao tronco que se apresenta com angulação entre $20^{\circ}$ e $60^{\circ}+$ código (3), totalizando de 5 a 6 pontos e, portanto, classificada pelo nível de ação 3 que sugere uma investigação e a introdução de mudanças.

Durante atividade de derrubada como um todo, apenas $20 \%$ das codificações encontradas, o operador se encontrou com a angulação do pescoço entre $0^{\circ}-10^{\circ}$ dada pelo código (2); por $30 \%$ do período, o operador permanece com o pescoço com angulação entre $10^{\circ}-20^{\circ}$ e em $50 \%$ do total, o pescoço do mesmo se encontra inclinado $20^{\circ}+$.

Segundo Másculo; Mattos (2011), a cabeça humana adulta pesa cerca de $4-5 \mathrm{~kg}$, sendo assim, quando ela é flexionada mais de $30^{\circ}$, os músculos do pescoço são tencionados para manter essa postura gerando uma sobrecarga no pescoço e ombros. Além disso, os mesmos ainda recomendam que o ideal é manter a cabeça o mais próximo possível da posição vertical e ressaltam que posturas inadequadas podem resultar em consequências graves ao sistema musculoesquelético, afetando vários segmentos corporais.

Ainda, a inclinação durante certo período de tempo intermitente pode causar fadigas musculares, as quais irão impedi-lo de realizar alguns movimentos com o pescoço sem que sinta algum tipo de dor (VERGARA, 2012).

Já, em relação a atividade de desgalhamento, a postura com maior representatividade foi a 214142121 definida como braços com angulação entre $20^{\circ}$ para frente ou para trás (2); antebraço entre $0^{\circ}-60^{\circ}$ indicado pelo código (1); punhos com $15^{\circ}+(4)$; rotação média de punho (1); pescoço inclinado entre $10^{\circ}-20^{\circ}+(3)$; tronco com inclinação entre $0^{\circ}-20^{\circ}+$, código (2), com pés e pernas bem apoiados e equilibrados (1) além de carga exercida pelo grupo A, entre 2 a $10 \mathrm{~kg}$, referente ao peso da motosserra, e o grupo B se apresenta sem carga ou com carga inferior a $2 \mathrm{~kg}$ intermitentemente foi a postura que mais utilizada e se enquadrou no nível 2 indicando a necessidade de realizar uma observação além de destacar que mudanças podem ser necessárias (Tabela 3).

Segundo Paschoarelli et. al (2008), para o antebraço, amplitudes de até $45^{\circ}$ são consideradas seguras para prono supinação porém, no caso da primeira postura, o operador se encontra com antebraço com angulação e $100^{\circ}+$, codificada pelo digito (3).

Englobando a atividade de derrubada, desgalhamento e toragem o operador se encontrou com antebraço fora do nível de amplitude máxima segura, ou seja, codificações (2) indicando angulação entre $60-100^{\circ}$ ou (3) correspondendo com a angulação maior que $100^{\circ}$, por $46,67 \%$ do período que, ao considerarmos uma jornada de trabalho de 8 horas, 0 mesmo estaria fora do limite seguro por 3,7 horas.

Ainda, constatou-se que o operador manteve o tronco inclinado mais de $60^{\circ}$, código (4), por $26,66 \%$ assim, totalizando 2 horas e $13 \mathrm{~min}$, tendo em vista uma jornada de trabalho diária de 8 horas (Tabela 3).

\subsection{REBA}

Ademais, considerando as codificações obtidas na avaliação postural utilizando o método REBA, a postura mais representativa da atividade de derrubada foi codificada como 
221242212 , onde o pescoço está inclinado entre $0^{\circ}$ e $20^{\circ}(2)$, o tronco se encontra ereto (2), o operador possui suporte nas duas pernas andando ou sentado (1), a carga exercida está entre 5 e $10 \mathrm{~kg}(2)$, os braços se comportam de maneira a estarem inclinados entre $45^{\circ}$ e $90^{\circ}(4)$, o antebraço possui angulação que varia de $0^{\circ}-60^{\circ}$ ou maior que $100^{\circ}$ (2), além do punho está com angulação oscilante em $15^{\circ}$ para cima ou para baixo (2) e a pega e atividade, foram consideradas boas (1) e com movimentos repetitivos (2), respectivamente.

A codificação descrita acima, se assemelha a postura mais representativa da atividade de desgalhamento 231231212 onde, ambas possuem o mesmo número de repetições, totalizando $20,37 \%$ da análise além de serem classificadas no nível de ação 2 onde se tem um risco médio e a intervenção é necessária. Ainda, as mesmas se diferenciaram somente no código referente ao tronco, aqui se encontra inclinado entre $0^{\circ}-20^{\circ}$ (3), os braços se encontram com angulações entre $20^{\circ}-45^{\circ}$ (3) e o antebraço se apresenta inclinado entre $60^{\circ}$ $100^{\circ}$ (1) (Tabela 3).

Entre as codificações demostradas na Tabela 3, o tronco se encontrou inclinado mais de $60^{\circ}$ (5) em oito posturas, sete das mesmas estão na atividade de desgalhamento e uma na derrubada. Equivalendo a 69,88\% (5 horas e $59 \mathrm{~min}$ ) para uma jornada de trabalho de 8 horas.

Segundo Batiz et. al (2012a), manter o tronco flexionado ou/e curvado para frente, aumenta excessivamente a pressão intradiscal exigindo grande esforço muscular de sustentação contra a ação da gravidade podendo provocar um processo de dor lombar quando adotada diariamente e/ou por períodos prolongados.

O nível de ação 3, onde o risco é considerado alto e a intervenção é necessária o quanto antes, foi mais encontrado na análise pelo método REBA e apresentou em oito das 30 posturas encontradas, ou seja, em 70,78\% da jornada (Tabela 3).

Todas as codificações enquadradas no nível de ação 3 possuíam em comum a codificação (3) referente ao pescoço inclinado para mais de $20^{\circ}$, além da carga entre 5 e $10 \mathrm{~kg}$ (2), a pega foi considerada boa (1) e a atividade codificada como movimentos repetitivos (2).

\subsection{Média ponderada das categorias de ação}

Agora, tendo em vista as categorias ou nível médio de ação da análise, considerando cada um dos métodos empregados, se enquadram entre 1,61 e 2,57. Para o método OWAS, a atividade de desgalhamento foi a que, considerando a categoria de ação média de 1,61, obteve melhor desempenho. Já a atividade de toragem, obteve pior desempenho uma vez que apresenta média de 2,28 onde a categoria 2 indica que postura deverá ser verificada durante a próxima revisão de rotina de trabalho e a 3 indica que a mesma merece atenção a curto prazo. Um fator que pode ter contribuído para as posturas da atividade de toragem terem obtido maior média de categoria de ação, é que as costas se encontram inclinadas e torcidas (4), pior código referente a esta parte do corpo, em 3 das 10 posturas descritas.

Já para o RULA, a atividade de toragem, assim como no método OWAS, também obteve pior desempenho uma vez que atingiu como nível de ação 2,47. O melhor desempenho ocorreu durante a atividade de desgalhamento, nível de ação 2 , indicou que a postura deve ser investigada e podem ser necessárias alterações.

Ainda, não diferente dos resultados obtidos para o método OWAS e RULA, o método REBA teve sua pior média de nível de ação durante a atividade de toragem, sendo classificado em 2,57 e, ao contrário dos demais, o melhor desempenho foi durante a atividade de derrubada sendo classificado em 2,06.

\subsection{Comparativo entre OWAS, REBA e RULA}

Ademais, numa tentativa de comparação dos diferentes métodos utilizados para fins ergonômicos além da estimação dos métodos mais utilizados, LAPERUTA et al. (2018), realizou uma análise de tendência do período 2004-2014 em publicações envolvendo métodos ergonômicos onde $\mathrm{O}$ OWAS, REBA e RULA aparecem em $4^{\mathrm{a}}, 5^{\mathrm{a}}$ e $6^{\mathrm{a}}$ posições, respectivamente. Foram encontradas 89 publicações que, em sua metodologia, utilizaram o método OWAS além de 69 que utilizaram o REBA e 52 que empregaram o RULA em suas análises.

Após essa conclusão, o mesmo autor aplicou um questionário a cinco profissionais, com objetivo de realizarem a avaliação dos métodos, atribuindo notas numa escala de 1-5.

Contudo, 3 dos 5 profissionais, consideraram o método OWAS de fácil utilização, obtendo média 4 de 5. Para os profissionais, o método tem como vantagem a possibilidade de visão geral do quadro postural, considerando a carga, a posição dos membros superiores e inferiores, costas, região cervical, punhos, quadril, etc. São desvantagens a dificuldade de aplicação em diversos casos, nível de detalhamento reduzido em posturas específicas (determinados segmentos corporais), demanda bastante tempo na análise, muito simples e com déficit de informações; dependendo do foco, precisa ser utilizado em associação a outro método como o REBA e/ou o RULA.

Já o REBA, foi classificado com média 3,75 de 5 e ganhou pontos por oferecer uma visão detalhada, a nível de diagnose, do quadro postural obtendo-se uma análise detalhada dos membros inferiores.

Para o RULA, obteve média de 3,8 e as observações feitas foram com relação à facilidade de usar, o fato de o mesmo avaliar vários segmentos e por ter um resultado bem preciso, fazendo uma análise detalhada dos membros superiores (a nível de diagnose).

Ademais, os três métodos descritos foram indicados para avalições de postos de trabalho, para avaliação postural e, exceto o OWAS, aparecem também com objeto de estudo sendo a repetição (LAPERUTA et. al 2018).

Entretanto, cabe ao usuário estar atento aos números de codificações totais referentes às várias partes do corpo apresentadas por cada um dos métodos a fim de determinar qual dos mesmos seria mais funcional aplicado ao seu caso.

Assim, havendo um interesse em analisar as posturas adotadas pelo operador referentes ao pescoço, por exemplo, não seria interessante utilizar o método OWAS, pois o mesmo sequer possui codificações especificas para o pescoço.

Por exemplo, comparando o método RULA e REBA, para a atividade de toragem, observou-se por meio da Tabela 2 , no caso do REBA, que o operador se manteve com o pescoço inclinado mais de $20^{\circ}$, código (3), por toda a análise. Já para o RULA, considerando as 10 codificações descritas na Tabela 2 e desconsiderando suas referidas repetições, o operador se manteve com pescoço inclinado entre $10^{\circ}-20^{\circ}$, código (4), por $50 \%$ da análise, além de permanecer o mesmo

Nativa, Sinop, v. 8, n. 3, p. 442-449, mai./jun. 2020. 
inclinado mais de $20^{\circ}$, código (5), por $50 \%$ da análise demonstrando assim, que o RULA, por ter 5 códigos referente ao pescoço, tem posturas com maior variabilidade de codificações uma vez que apresenta mais possibilidades, favorecendo, portanto, um melhor enquadramento das posturas observadas em angulações que, de fato, se mostrem específicas para as mesmas.

\section{CONCLUSÕES}

Dado o exposto, posturas em que o operador apresente qualquer uma das codificações abaixo, devem ser modificadas e evitadas, são elas: a costa inclinada, inclinada e torcida, o troco inclinado, os dois braços acima do nível dos ombros, o antebraço com amplitudes maiores que $45^{\circ}$, o pescoço com qualquer ângulo de inclinação e, ainda, todas as posturas que foram classificadas nas categorias ou níveis de ação que indiquem uma intervenção próxima ou imediata.

Desta forma, seis posturas do método OWAS, oito do RULA e vinte e duas referentes ao método REBA, podem ou devem sofrer intervenções próxima ou imediatas, tendo em vista sua categoria ou nível de ação.

\section{RECOMENDAÇÕES}

É fundamental evitar manter-se com as costas, tronco, pescoço, punho e demais partes do corpo inclinado e/ou torcido. Ainda, o operador deve alternar posturas nas quais as pernas se encontrem mal apoiadas e desequilibradas.

Ademais, a cabeça não deve ser flexionada mais de $30^{\circ}+$, os antebraços devem estar inclinados até $45^{\circ}$, manter os braços abaixo do nível do ombro e todas as posturas que foram classificadas nas categorias ou níveis de ação que tenham indiquem uma intervenção próxima ou imediata.

Vale ressaltar que, pensando na manutenção física e mental, seria de suma importância o estabelecimento de pausas para descanso alternadas e com maior frequência, ao longo da jornada de trabalho afim de reduzir possíveis danos a saúde do trabalhador.

Ainda, cabe ao operador de motosserra a adoção de Equipamentos de Proteção Individual (EPI), tais como luvas anti-vibrações, capacete com protetor facial em tela e com proteção auricular, além de botina e vestimenta adequado, uma vez que os mesmos evitam e protegem os funcionários de situações de risco como, por exemplo, a perfurações e contato com animais peçonhentos.

\section{REFERÊNCIAS}

BARBOSA, P. R.; FIEDLER, N. C.; CARMO, F. C. A; MINETTE, L. J.; SILVA, N. E. Análise de posturas na colheita florestal semimecanizada em áreas declivosas. Revista Árvore, Viçosa, v. 38, n. 4, p. 733-738, 2014. DOI: http:/ /dx.doi.org/10.1590/S010067622014000400016

BATIZ, E. C.; NUNES, J. I. S.; LICEA, O. E. A. Prevalência dos sintomas musculoesqueléticos em movimentadores de mercadorias com carga. Produção, São Paulo, v. 23, n. $1, \quad$ p. $168-177$, 2012a. DOI: http://dx.doi.org/10.1590/S0103-65132012005000030

BATIZ, E. C.; VERGARAB, L. G. L; LICEAC, O. E. A. Análise comparativa entre métodos de carregamento de cargas e análise postural de auxiliares de enfermagem. Produção, São Paulo, v. 22, n. 2, p. 270-283, 2012b.
DOI:

http://dx.doi.org/10.1590/S010365132012005000013

CORLETT, E. N.; WILSON, J. R. Evaluation of human work. 3. ed. Boca Raton: CRC Press, 2005. 1048 p.

DUL, J.; WEERDMEESTER, B. Ergonomia prática. 3. ed. São Paulo: Blucher, 2012. 163 p.

LAMARÃO, A. M.; COSTA, L. C. M.; COMPER, M. L. C.; PADULA, R. S. Translation, cross-cultural adaptation to Brazilian- Portuguese and reliability analysis of the instrument Rapid Entire Body Assessment-REBA. Brazilian Journal of Physical Therapy. São Carlos, v. 18, n. 3, p. 211-217, 2014. DOI: http:/ /dx.doi.org/10.1590/bjpt-rbf.2014.0035

LAPERUTA, D. G. P.; OLIVEIRA, G. A.; PESSA, S. L. R.; DA LUZ, R. P. Revisão de ferramentas para avaliação ergonômica. Revista Produção Online, Piracicaba, v. 18, n. 2, p. 665-690, 2018. DOI: https://dx.doi.org/10.14488/1676-1901.v18i2.2925

LEONELLO, E. C.; GONÇALVES, S. P.; FENNER, P. T. Efeito do tempo de experiência de operadores de Harvester no rendimento operacional. Revista Árvore, v. 36, n. 6, p. 1129-1133, 2012. DOI: http://dx.doi.org/10.1590/S0100-67622012000600013

LOPES, E. A.; CANTO, J. L. Produtividade e custos de dois sistemas de exploração e transporte de lenha na Caatinga. Nativa, Sinop, v. 6, n. 2, p. 207-212, 2018. DOI: http://dx.doi.org/10.31413/nativa.v6i2.4697

MAIA, J. M.; SOUSA, V. F. O.; LIRA, E. H. A.; LUCENA, A. M. A. Motivações socioeconômicas para a conservação e exploração sustentável do bioma Caatinga. Desenvolvimento Meio Ambiente, Curitiba, v. 41, p. 295-310, 2017. DOI: http://dx.doi.org/10.5380/dma.v41i0.49254

MÁSCULO, F.; MATTOS, U. Higiene e segurança do trabalho para engenharia de produção. Rio de Janeiro, RJ. Editora: Elsevier, 2011. p. 333-334.

NORMA REGULAMENTADORA - NR 17. Ergonomia. In: Segurança e Medicina do Trabalho. 70. ed. São Paulo: Atlas, 2012. p. 321-334.

PASCHOARELLI, L. C.; DE OLIVEIRA, A. B.; GIL COURY, H. J. C. Assessment of the ergonomic design of diagnostic ultrasound transducers through wrist movements and subjective evaluation. International Journal of Industrial Ergonomics, Amsterdam, v. 38, n. 11-12, p. 999-1006, 2008. DOI: https://dx.doi.org/10.1016/j.ergon.2008.01.013

SANTOS-SILVA, J.; FRAGOMENI, S. M.; TOZZI, A. M. G. D. A. Taxonomic revision of the species of Mimosa ser. Leiocarpae sensu lato (Leguminosae-Mimosoideae). Rodriguésia, Rio de Janeiro, v. 66, n. 1, p. 95-154, 2015. DOI: http://dx.doi.org/10.1590/2175-7860201566107

SILVA, E. P.; MINETTE, L. J.; SANCHES, A. L. P.; DE SOUZA, A. P.; SILVA, F. L.; MAFRA, S. C. T. Prevalência de sintomas osteomusculares em operadores de máquina de colheita florestal. Revista Árvore, Viçosa, v. 38 , n. 4 , p. 739-745, 2014. DOI: http://dx.doi.org/10.1590/S0100-67622014000400017

SILVA, L. B. da; SANTOS, F. A. R. dos; GASSON, P.; CUTLER, D. Estudo comparativo da madeira de Mimosa ophthalmocentra Mart. ex Benth e Mimosa tenuiflora (Willd.) Poir. (Fabaceae-Mimosoideae) na caatinga nordestina. Acta Botanica Brasilica, Feira de Santana, v. 25, n. 2, p. 301-314, 2011. DOI: 
Silva et al.

http://dx.doi.org/10.1590/S0102-33062011000200006

VERGARA, L. G. L.; DE LIMA NUNES, I. M;

RODRIGUES, I. N; DA SILVA CORREIA, L. C; DA SILVA, V. Análise Ergonômica da atividade de Jardinagem e Paisagismo. Produção em Foco, Joinville, v. 2, n. 1, p. 9, 2012. DOI: https://dx.doi.org/10.14521/P2237-

5163.2012.0002.0005 